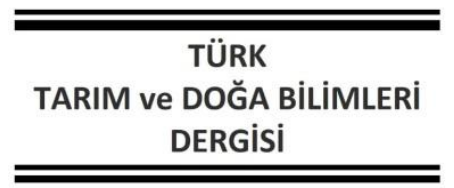

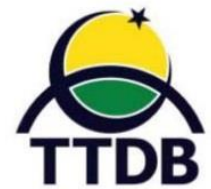

www.dergipark.gov.tr/turkjans Araştırma Makalesi

\title{
Şanlıurfa Yöresi Akkaraman ve İvesi Koyunlarında Mitokondriyal Sitokrom $b$ (Cyt $b$ ) Gen Dizisine Göre Filogenetik Analizler
}

\author{
Selahaddin KiRAZ ${ }^{1}$, Mehmet Sait EKINCi², Seyrani KONCAGÜL ${ }^{3}$ \\ ${ }^{1}$ Harran Üniversitesi, Ziraat Fakültesi, Zootekni Bölümü, Şanlıurfa \\ ${ }^{2}$ Kahramanmaraş Sütçü İmam Üniversitesi, Ziraat Fakültesi, Zootekni Bölümü, Kahramanmaraş \\ ${ }^{3}$ Ankara Üniversitesi, Ziraat Fakültesi, Zootekni Bölümü, Ankara \\ *Sorumlu yazar: skiraz73@gmail.com.tr
}

Geliş Tarihi: 22.09.2020, Düzeltme Geliş Tarihi: 14.01.2021, Kabul Tarihi: 15.01.2021

Öz

Bu çalışmada, Şanlıurfa yöresindeki Akkaraman (AK) ve ivesi (IV) koyunlarının filogenetik yapıları moleküler tekniklerle belirlenmeye çalışımıştır. Araştırmanın hayvan materyalini, Şanlıurfa ve yöresinde yetiştirilen Akkaraman (AK) ve İvesi (IV) koyunları oluşturmuştur. Koyunlardan genomik DNA izolasyonu için kıl örnekleri toplanmış ve tüm örneklerden genomik DNA izole edilmiştir. Koyun DNA örneklerinde mitokondriyal Sitokrom b (Cyt $b$ ) gen bölgelerini çoğaltmak için gerekli ileri ve geri primerler tasarlanmıştır. Koyun Cyt $b$ gen bölgeleri polimeraz zincir reaksiyonu tekniği (PZR) ile çoğaltılmıştır. PZR ürünlerinin gen dizi bilgileri elde edilmiştir. Populasyonlar için toplam bölge sayısı, G+C oranı, polimorfik bölge sayısı (S), haplotip sayısı (h), haplotip farklılı̆ı $\left(H_{d}\right)$ ve nükleotid farklılı̆ı $(\pi)$ değerleri hesaplanmıştır. Koyun haplotiplere ait Cyt $b$ gen dizileri ile referans diziler (A, B, C, D, ve E soyları) birlikte oluşturulan N-J filogenetik ağaçta, 16 haplotipten, 6'sı B soyunda (IV01, AK13, AK09, IV06, AK16, IV05), 1'i A soyunda (IV12), 1'i E soyunda (AK04) 5'i C soyunda (AK12, AK02, IV16, AK01, IV08, IV03) yer almış, AK06 ve IV13 farklı kümelenmiştir. Sonuç olarak, Şanlıurfa yöresi Akkaraman ve İvesi koyunları Cyt $b$ gen bölgesi gen dizileri belirlenmiştir.

Anahtar kelimeler: Koyun, mtDNA, filogenetik, moleküler teknikler

\section{Phylogenetic Analysis of Awassi and Akkaraman Sheep in Şanlıurfa Province based on Mitochondrial Cytochrome $b$ (Cyt b) Gene}

\begin{abstract}
In this research, determination of phylogenetic tree of sheep in Şanlıurfa province using molecular techniques was the main goal. White Karaman (AK) and Awassi sheep (IV) breed raised in Şanlıurfa province were used as the animal materials. Fleece samples were collected for genomic DNA isolation in sheep, and genomic DNAs were isolated in all the samples. In DNA samples, necessary forward and reverse primers were designed to amplify mitochondrial Cytochrome $\mathrm{b}(\mathrm{Cyt} b)$ gene region. Mitochondrial Cyt $b$ gene region were amplified by applying polymerase chain reaction (PCR) technique, and gene sequence information of PCR products were obtained. The rate of $\mathrm{G}+\mathrm{C}$, number of polymorphic site $(\mathrm{S})$, number of haplotypes $(\mathrm{h})$, haplotype diversity $\left(\mathrm{Hd}_{\mathrm{d}}\right)$, nucleotide diversity $(\pi)$ and total number of region for all populations were calculated. $\mathrm{N}-\mathrm{J}$ phylogenetic tree formed in this research using sheep haplotype Cyt $b$ sequences and reference sequences ( for A, B, C, D and E lineage), 6 haplotypes (IV01, AK13, AK09, IV06, AK16, IV05) out of 16 haplotypes were in B lineage, 1 haplotype (IV12) were in A lineage, 1 haplotype (AK04) were in E lineage, 5 haplotypes (AK12, AK02, IV16, AK01, IV08, and IV03) were in C lineage, and AK06 and IV13 were in different group. In conclusion, in White Karaman and Awassi sheep, raised in Şanlıurfa province; gene sequences of Cytochrome b gene were determined.
\end{abstract}

Key words: sheep, mtDNA, phylogenetic, molecular techniques 


\section{Giriş}

En erken evcilleştirilmiş hayvan olarak evcil koyun (Ovis aries), insanlar için et, süt ve kürk gibi çok faydalı ürünler sağlamanın yanında neolitik devre uzanan erken dönemlerde tarım, ekonomi, kültür ve hatta din gibi konularda önemli bir rol oynamıştır. Yakın Doğu'daki arkeolojik bölgelerdeki bulgular, muhtemelen koyunun yaklaşık 8.0009.000 yıl önce Yakın Doğu'daki Fertile Crescent bölgesinde ilk evciltilmiş olabileceğini ileri sürmektedir (Zeder ve Hesse, 2000). Muflon (Ovis musimon veya Ovis orientalis), urial (Ovis vignei) ve argali (Ovis ammon) gibi bazı yabani koyun türlerinin modern evcil koyunun atası olduğu veya belirli ırklara katkılarının bulunduğu ileri sürülmüştür (Zeuner, 1963; Ryder, 1984).

Evcil koyun genomu $(2 n=54), 26$ çift otozomal kromozomu, 2 çift cinsiyet kromozomu ve mitokondriyal genomu içermektedir. Ökaryotik hücrelerin nükleusunda bulunan DNA'ya (nDNA) ek olarak az miktarda sitoplazmik DNA'ya da rastlanır. $\mathrm{Bu}$ sitoplazmik DNA'lar hayvanların mitokondrilerinde (mtDNA), bulunmakta olup çift sarmal ve halkasal yapıdadır (Hiendleder ve ark., 1998a). mtDNA; populasyonların tanımlanması, populasyonların ve türlerin orijinlerinin belirlenmesi, populasyonların biyocoğrafik dağılımlarının belirlenmesi, alttür içerisindeki haplotiplerin belirlenmesi, populasyonlar arasındaki gen akışı seviyelerinin tahmin edilmesi, anaya ait (maternal) kalıtım modellerinin izlenmesi, populasyonlar içi/arası genetik varyasyonun hesaplanması, populasyonların genetik benzerlik veya farklılıklarından yararlanılarak filogenetik ilişkilerin tespit edilmesi gibi çalışmalarda moleküler belirteç (özellikle D-loop ve Sitokrom b gen bölgeleri) olarak kullanılmaktadır (Meadows ve ark. 2007). Mitokondriyal DNA, sığır (Bradley ve ark., 1996; Loftus ve ark., 1994; Troy ve ark., 2001), keçi (Joshi ve ark., 2004; Machugh ve Bradley, 2001; Luikart ve ark., 2001; Manen ve ark., 2001; Sultana ve ark., 2003) ve koyunun (Hiendleder ve ark., 1998b; 2002, Pardeshi ve ark., 2007; Pedrosa ve ark., 2007) orjininin araştırılmasında kullanılmıştır.

Koyun mitokondri genomları; protein kodlayan 13 bölge (sitokrom c oksidaz kompleksi I, II ve III altbirimleri, ATPaz kompleksi 6 ve 8 altbirimleri, NADH dehidrogenez 1, 2, 3, 4L, 4, 5 ve 6 ile sitokrom b), 2 ribosomal RNA bölgesi (12S rRNA, 16S rRNA), kontrol bölgesi (D-loop) ve 22 tRNA (60-75 bç) bölgelerinden oluşmaktadır (Hiendleder ve ark., 1998a). Koyun mtDNA'sı 16640 bç uzunluktadır.

Önceki yıllarda yapılan çalışmalarda, evcil koyunların (Ovis aries) Avrupa (tip B) ve Asya (tip A) haplo-gruplar olarak iki büyük sınıfa ayrıldığı belirtilmiştir (Hiendleder ve ark., 1998a, 1998b, 1999). Bununla birlikte,

Güncel olarak son zamanlarda, koyunlar üzerinde yapılan moleküler filogenetik ve filocoğrafik çalışmalarda evcil koyunların A, B, C, D ve $E$ olmak üzere 5 farklı maternal soya ayrıldığı bildirilmiştir (Meadows ve ark. 2007).

Çalışmanın amacı; Şanlıurfa yöresi Akkaraman ve İvesi koyunlarında Mitokondriyal Cyt $b$ gen dizilerinin belirlenmesi ile mtDNA polimorfizmini ve mtDNA haplotiplerini tespit etmektir. Bu çalışma ile koyunların filogenetik yapıları ile filogenetik ilişkiler belirlenecektir. Ayrıca, bu çalışmanın Şanlıurfa yöresi Akkaraman ve İvesi koyunlarının gen dizi bilgilerinin Gen Bankasında depolanması, koyunlar üzerinde yapılan filogenetik çalışmalara, Hayvan ıslahı, biyoçeşitlilik ve ulusal gen koruma çalışmalarına katkı sağlaması amaçlanmaktadır..

\section{Materyal ve Metot Hayvan Materyali ve Örnek Toplama}

Araştırmanın hayvan materyalini, Şanlıurfa ve yöresinde yetiştirilen Akkaraman ve İvesi koyunları ırkları oluşturmuştur. Şanlıurfa merkez ve ilçelerine ait farklı güzergahlarda tesadüfi olarak karşılaşılan koyun sürülerinden DNA izolasyonu için kıl örnekleri toplanmıştır. Seçilen hayvanların birbirlerine akraba olmaması için her sürüden bir örnek alınmıştır. Kıl örnekleri, doğrudan temas ve kontaminasyonu önlemek için eldivenlerle hayvanların üst sırt boyun kısımdan çekilerek toplanmıştır.

\section{Moleküler Çalışmalar}

Moleküler çalışmalar, Kahramanmaraş Sütçü İmam Üniversitesi Ziraat Fakültesi Zootekni Bölümü Biyoteknoloji ve Gen Mühendisliği Laboratuarında gerçekleştirilmiştir. Koyunlardan toplanan kıl örneklerinden, Sambrook ve ark. (1989)'nın fenol/kloroform+Proteinaz K yöntemi modifiye edilerek toplam genomik DNA izolasyonu yapılmıştır.

Koyun DNA örneklerinde mitokondriyal DNA Sitokrom b (Cyt $b)$ gen bölgelerini çoğaltmak için gerekli ileri ve geri primerlerin tasarlanması amacıyla öncelikle, Gen Bankası internet portalından (http://www.ncbi.nlm.nih.gov), evcil koyun (Ovis aries) için komple mitokondriyal genom (Ovis aries mitochondrion, complete genome) nucleotide arama modu ile sorgulanarak referans dizi bilgileri (RefSeq) temin edilmiştir. Ovis aries mtDNA için referans dizi erişim kodu: NC_001941'dir. Koyun için referans mtDNA genomun $C y t$ ben bölgesine ait diziler nükleotid BLAST (blastn) yapılarak organizmalar (Ovis 
taxid:9935) için dizi seti (hedef dizi: 250 adet) oluşturulmuştur. Oluşturulan dizi setinde Clustal W (Thompson ve ark., 1994) programı kullanılarak koyun $C y t b$ gen bölgeleri için homolog bölgeler belirlenmiş ve bu bölgelerden primer çiftleri tasarlanmıştır. Primerler, Favorgen (Tayvan) firmasına sentezlettirilmiştir. PCR Amplifikasyonu için, $1.0 \mu \mathrm{l}$ ileri ve $1.0 \mu \mathrm{l}$ geri primer $(10 \mathrm{pM} / \mu \mathrm{l})$, $1.0 \mu \mathrm{ldNTP} \operatorname{mix}(500 \mu \mathrm{M} / \mu \mathrm{l}), 4.0 \mu \mathrm{l}$ 10X PCR buffer $\left(+\mathrm{MgCl}_{2}\right), 1.0 \mu \mathrm{l}$ kalıp DNA $(120 \mathrm{ng} / \mu \mathrm{l}), 2 \mathrm{U}$ Taq DNA polimeraz $(5 \mathrm{U} / \mu \mathrm{l})$ içeren karışım $0.2 \mathrm{ml}$ PCR tüpleri içerisinde $32 \mu \mathrm{l} \mathrm{dH}_{2} \mathrm{O}$ ile toplam $40 \mu \mathrm{l}$ olarak hazırlanmıştır. PCR reaksiyon şartları; ön denaturasyon için $95^{\circ} \mathrm{C}^{\prime}$ de 2 dakika ve tek döngü, denatürasyon için $94{ }^{\circ} \mathrm{C}^{\prime}$ de $60 \mathrm{sn}$, yapışma için 60 ${ }^{\circ} \mathrm{C}$ 'de 60 sn, uzama için $72{ }^{\circ} \mathrm{C}^{\prime}$ de 2 dakika ve bu aşamalar için 30 döngü, son uzama için $72{ }^{\circ} \mathrm{C}^{\prime}$ de 5 dakika tek döngü olarak ayarlanmıştır.

Akkaraman ve İvesi koyun ırklarından Cyt $b$ gen bölgelerinin PZR amlifikasyonu gerçekleşmiş örneklerde ileri $(F)$ ve geri $(R)$ zincir olmak üzere dizileme işlemi İontek (İstanbul) firmasına yaptırımıştır. Gen dizileme için örnekler $50 \mu \mathrm{l}$ olarak (25 $\mu \mathrm{l}$ PZR ürünü $\left.+25 \mu \mathrm{l} \mathrm{ddH}_{2} \mathrm{O}\right)$ hazırlanmıştır. DNA sekasları değerlendirmeler sonucunda, her bir ırktan 16 hayvana ait Cyt $b$ gen dizi bilgilerine göre dizi veri setleri oluşturulmuştur. Dizi veri setinde Akkaraman 1 nolu örnek "AK01", İvesi 1 nolu örnek "IV01" şeklinde tüm örnekler kodlanmıştır.

DNA Polimorfizmi ve Filogenetik Analizler
Populasyonlar için toplam bölge sayısı, polimorfik bölge sayısı (S), haplotip sayısı (h), haplotip farklılığı ( $\mathrm{H}_{\mathrm{d}}$ : haplotype diversity), nükleotid farklılığı ( $\pi$ : nucleotide diversity), ortlama nükletid farklılığı sayısı (k) ve Tajima'nın $D$ test istatistiği değerleri DnaSP 5.0 (Librado ve Rozas, 2009), programı kullanılarak belirlenmiştir.

Koyunlarda filogenetik yapılarının araştırılmasında Cyt b gen bölgelerinde DNA polimorfizmine göre öncelikle temel ve sonra ileri Filogenetik analizler yapılmıştır. Temel filogenetik analizler; her bir ırkta genetik ilişkileri göstermek ve haplotipleri belirlemek amacıyla UPGMA (Unweighted Pair Group Method with Arithmetic mean) yöntemine göre MEGA 4.0.1 programında (Tamura ve ark., 2007) Kimura-2-parametre model (Kimura, 1980) kullanılarak yapılmıştır. Bu çalışmada ileri filogenetik analizler, NeighbourJoining (NJ) (Saitou ve Nei, 1987) metoduna göre Kimura-2-parametre+Gamma dağılımı (K2P+Г) modeli kullanılarak MEGA 4.0.1 programında (Tamura ve ark., 2007) yapılmıştır. Nodların (ağaç kolları) güvenirliğinin test edilmesinde Bootstrap testi (1000 tekrarlı) kullanılmıştır (Nei ve Kumar, 2000). Ayrıca ileri filogenetik analizlerde, Türkiye yerli koyun ırkları ile yapılan önceki çalışmalara ait dizi bilgileri Gen Bankasından (NCBI) temin edilerek birlikte filogenetik ağaç oluşturulmuştur.

\begin{tabular}{llcrc}
\hline Primerler & Dizi $(5 \rightarrow 3)$ & Uzunluk & Pozisyon & $\mathrm{Tm}\left[{ }^{\circ} \mathrm{C}\right]$ \\
\hline OVS CYT B (F) & CAACATCCGAAAAACCCACC & 20 & $6-25$ & 66.14 \\
OVS CYT B $(\mathrm{R})$ & GGAGGTTGTTTTCGATGATGC & 21 & $1109-1129$ & 65.45
\end{tabular}

Koyun Cyt b geni: 1140 bç, PZR ürünü: 1124 bç (NC_001941)

ATGATCAACATCCGAAAAACCCACCCACTAATAAAAATTGTAAACAACGCATTCATTGATCTCCCAGCTCCATCAAATATTT
CATCATGATGAAACTTTGGCTCTCTCCTAGGCATTTGCTTAATTTTACAGATTCTAACAGGCCTATTCCTAGCAATACACTAT
ACACCTGACACAACAACAGCATTCTCCTCTGTAACCCACATTTGCCGAGACGTAAACTATGGCTGAATTATCCGATATATAC
ACGCAAACGGGGCATCAATATTTTTTATCTGCCTATTTATGCATGTAGGACGAGGCCTATACTATGGATCATATACCTTCCT
AGAAACATGAAACATCGGAGTAATCCTCCTATTTGCGACAATAGCCACAGCATTCATAGGCTATGTTTTACCATGAGGACA
AATATCATTCTGAGGAGCAACAGTTATTACCAACCTCCTTTCAGCAATTCCATATATTGGCACAAACCTAGTCGAATGAATC
TGGGGAGGATTCTCAGTAGACAAAGCTACCCTCACCCGATTTTTCGCCTTTCACTTTATTTTCCCATTCATCATCGCAGCCCT
CGCCATAGTTCACCTACTCTTCCTCCACGAAACAGGATCCAACAACCCCACAGGAATTCCATCGGACACAGATAAAATTCCC
TTCCACCCTTATTACACCATTAAAGACATCCTAGGTGCTATCCTACTAATCCTCATCCTCATGCTACTAGTACTATTCACGCCT
GACTTACTCGGAGACCCAGACAACTACACCCCAGCAAACCCACTTAACACTCCCCCTCACATCAAACCTGAATGATACTTCC
TATTTGCGTACGCAATCTTACGATCAATCCCTAATAAACTAGGAGGAGTCCTCGCCCTAATCCTCTCAATCCTAGTCCTAGT
AATTATACCCCTCCTCCATACATCAAAGCAACGGAGCATAATATTCCGACCAATCAGTCAATGTATATTCTGAATCCTAGTA
GCCGACCTATTAACACTCACATGAATTGGAGGCCAGCCAGTTGAACACCCCTACATCATTATTGGACAACTAGCATCTATTA
TATATTTCCTTATCATTCTAGTCATAATACCAGTAGCTAGCATCATCGAAAACAACCTCCTAAAATGAAGA




\section{Bulgular ve Tartışma}

Akkaraman ve İvesi koyunlarından toplanan tüm kıl örneklerinde Fenol-Kloroform+ Proteinaz $\mathrm{K}$ yöntemi ile genomik DNA izole edilmiştir. Akkaraman ve İvesi koyunlarından izole edilen DNA'ların agaroz jel görüntüsü sırasıyla Şekil 1 ve Şekil 2'de verilmiştir.

İole edilen DNA örneklerinden, Cyt $b$ gen bölgeleri için tasarlanan primerler kullanılarak PZR amlifikasyon çalışmaları yürütülmüştür. Tüm örneklerde PZR ürünleri elde edilmiştir. Evcil Koyunlarda Cyt $b$ gen bölgesi 1140 bç

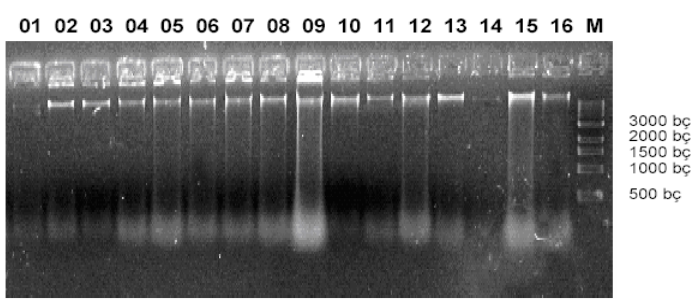

Şekil 1. Akkaraman koyunlarından izole edilen DNA'lar (M: marker)

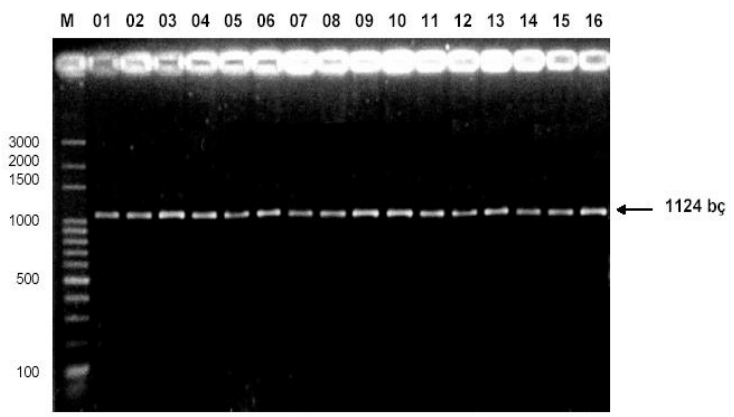

Şekil 3. Akkaraman koyunlarında Cyt $b$ geni PZR ürünü jel görüntüsü

Akkaraman ve İvesi koyunlarında $C y t b$ gen dizi bilgileri analiz edilerek DNA polimorfizm özellikleri belirlenmiştir (Çizelge 1). Akkaraman koyunlarında, Cyt $b$ geninde 16 polimorfik bölge ve 11 haplotip tespit edilmiştir. Akkaraman koyunlarında, haplotip ve nükleotid faklılığı sırasıyla, $0.908 \pm 0.0190$ ve $0.00823 \pm 0.00039$ olarak bulunmuştur. İvesi koyunlarında ise 12 polimorfik bölge ve 8 haplotip tespit edilmiştir. İvesi koyunlarında, haplotip ve nükleotid faklılığı sırasıyla $0.825 \pm 0.0268$ ve $0.00701 \pm 0.00052$ olarak bulunmuştur.

Akkaraman ve İvesi koyunları Cyt $b$ gen dizileri birlikte değerlendirildiğinde 18 polimorfik bölge ve 16 haplotip tespit edilmiştir (Çizelge 2). Koyunlarda, haplotip ve nükleotid faklılığı değerleri uzunluğundadır, tasarlanan OVS CYTB (F) ve OVS CYTB (R) primerleri ile bu genin 1124 bç'lik kısmı Akkaraman ve İvesi koyunlarında PZR ile çoğaltılmıştır (Şekil 3 ve Şekil 4).

Akkaraman ve İvesi koyunları Cyt $b$ gen bölgelerinin PZR ürünlerinin gen dizi analiz sonuçları elde edilmiştir. Akkaraman ve İvesi koyunlarında Cyt $b$ gen bölgeleri için elde edilen sırasıyla 1124 bç PZR ürünlerinden, dizilerin düzenlenmesi ve değerlendirilmesi sonucunda, sırasıyla 518 bç gen dizi bilgileri elde edilmiştir.

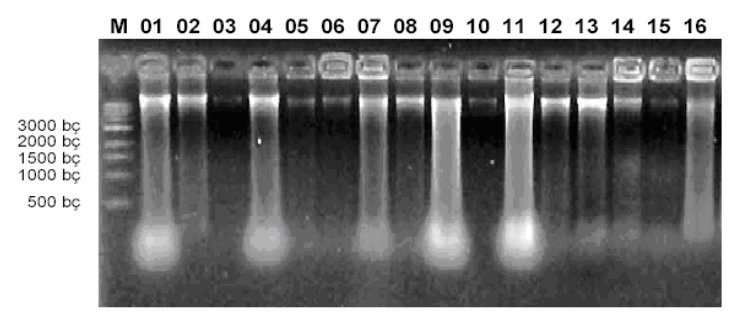

Şekil 2. İvesi koyunlarından izole edilen DNA'lar (M: marker)

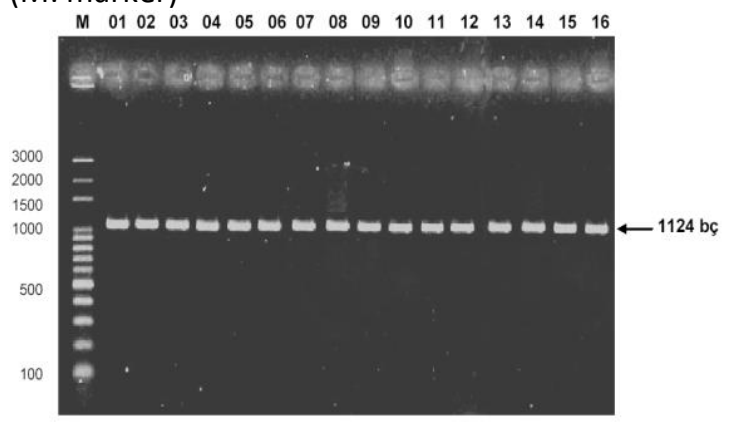

Şekil 4. İvesi koyunlarında Cyt $b$ geni PZR ürünü jel görüntüsü

sırasıyla, $0.857 \pm 0.0127$ ve $0.00764 \pm 0.00026$ olarak bulunmuştur. Belirlenen 18 polimorfik bölgede tüm nükleotid yer değiştirmeler transisyon şeklindedir.

Çizelge 1 incelendiğinde, koyunlarda Cyt $b$ genine göre haplotip sayısı, haplotip ve nükleotid faklılığı bakımından Akkaraman koyunlarında genetik çeşitliliğin İvesi koyunlarına nazaran fazla olduğu görülmektedir.

Akkaraman haplotipleri arasında genetik uzaklıkların 0.00173-0.01940, İvesi haplotipleri arasında ise 0.00187-0.0210 arasında olduğu görülmüştür (Çizelge 3 ve 4). 
Çizelge 1. Koyunlarda Cyt $b$ gen bölgesine göre DNA polimorfizmi

\begin{tabular}{lccc}
\hline Özellikler & Akkaraman & Ivesi & Genel \\
\hline Toplam bölge sayısı & 578 & 535 & 518 \\
G+C & 0.439 & 0.441 & 0.444 \\
Polimorfik bölge sayısı (S) & 16 & 12 & 18 \\
Haplotip sayısı (h) & 11 & 8 & 16 \\
Haplotip farklılığı Hd: & $0.908 \pm 0.0190$ & $0.825 \pm 0.0268$ & $0.857 \pm 0.0127$ \\
Nukleotid farklılığı & $0.00823 \pm 0.00039$ & $0.00701 \pm 0.00052$ & $0.00764 \pm 0.00026$ \\
Ort. nükletid farklılı̆ı sayısı (k) & 4.75833 & 3.75000 & 3.95968 \\
Tajima'nın D test istatistiği & -0.05194 & 0.14114 & -0.38804 \\
\hline
\end{tabular}

Çizelge 2. Koyunlarda Cyt $b$ gen bölgesine göre belirlenen haplotipler

\begin{tabular}{|c|c|c|c|c|c|c|c|c|c|c|c|c|c|c|c|c|c|c|c|c|}
\hline & & & & & & & & & & & & 1 & 1 & 1 & 1 & 1 & 1 & 1 & 1 & 1 \\
\hline & & & 1 & 2 & 3 & 4 & 5 & 6 & 7 & 8 & 9 & 0 & 1 & 2 & 3 & 4 & 5 & 6 & 7 & 8 \\
\hline & \multirow{3}{*}{\multicolumn{2}{|c|}{ Haplotipler }} & 3 & 3 & 3 & 3 & 3 & 3 & 3 & 4 & 4 & 4 & 5 & 6 & 6 & 7 & 7 & 7 & 7 & 7 \\
\hline & & & 0 & 2 & 2 & 3 & 6 & 9 & 9 & 4 & 7 & 9 & 5 & 9 & 9 & 0 & 1 & 3 & 3 & 4 \\
\hline & & & 9 & 4 & 8 & 1 & 4 & 3 & 6 & 4 & 6 & 5 & 2 & 3 & 6 & 0 & 1 & 5 & 8 & 1 \\
\hline & NC_001941 & $\mathrm{n}$ & $\mathrm{C}$ & C & C & G & G & $T$ & $T$ & C & $A$ & $\mathrm{G}$ & $\mathrm{T}$ & $\mathrm{T}$ & $\mathrm{T}$ & C & C & C & $\mathrm{G}$ & $\mathrm{T}$ \\
\hline 1 & IV12 & 11 & $T$ & . & . & . & . & . & . & . & . & $A$ & . & . & . & . & . & . & . & . \\
\hline 2 & IV03 & 1 & $\mathrm{~T}$ & . & $T$ & . & . & C & C & $\mathrm{T}$ & G & A & C & . & C & . & . & $T$ & . & . \\
\hline 3 & IV13 & 1 & . & . & . & . & . & C & C & $\mathrm{T}$ & G & $A$ & C & . & . & . & . & $T$ & . & . \\
\hline 4 & IV16 & 1 & $T$ & . & $\mathrm{T}$ & . & . & C & C & . & G & A & . & . & . & . & . & $\mathrm{T}$ & . & . \\
\hline 5 & IV08 & 1 & $\mathrm{~T}$ & . & $\mathrm{T}$ & . & . & . & . & . & G & $A$ & . & . & $C$ & . & . & $T$ & . & . \\
\hline 6 & IV05 & 6 & . & . & . & . & . & . & . & . & . & . & . & . & . & . & . & . & . & . \\
\hline 7 & IV06 & 1 & . & . & . & A & . & . & . & . & . & . & . & . & . & . & . & . & . & . \\
\hline 8 & IV01 & 2 & . & . & . & . & . & . & . & . & . & . & . & C & . & . & . & . & . & . \\
\hline 9 & АК02 & 1 & $\mathrm{~T}$ & . & $\mathrm{T}$ & . & . & C & C & . & G & $A$ & . & . & C & . & . & $T$ & . & $C$ \\
\hline 10 & AK12 & 1 & $T$ & . & $T$ & . & . & C & C & . & G & A & . & . & C & . & . & $\mathrm{T}$ & . & . \\
\hline 11 & AK01 & 1 & $\mathrm{~T}$ & . & . & . & . & C & C & . & G & A & . & . & C & . & . & $\mathrm{T}$ & . & . \\
\hline 12 & AKO4 & 1 & $\mathrm{~T}$ & . & . & . & . & C & . & . & G & A & . & . & C & . & $\mathrm{T}$ & . & A & . \\
\hline 13 & AK06 & 1 & $\mathrm{~T}$ & . & . & . & . & . & C & . & . & . & . & . & C & . & $\mathrm{T}$ & $T$ & . & . \\
\hline 14 & AK09 & 1 & . & $\mathrm{T}$ & . & . & . & . & . & . & . & . & . & . & . & . & . & . & . & . \\
\hline 15 & AK13 & 1 & . & . & . & . & . & . & . & . & . & . & . & . & . & $T$ & . & . & . & . \\
\hline 16 & AK16 & 1 & . & . & . & . & A & . & . & . & . & . & . & . & . & . & . & . & . & . \\
\hline
\end{tabular}

Çizelge 3. Akkaraman haplotipleri arasında Cyt $b$ genine göre genetik uzaklıklar $(\mathrm{K} 2 \mathrm{P}+\Gamma)$

\begin{tabular}{ccccccccccc}
\hline Haplotipler & $\mathrm{H} 1$ & $\mathrm{H} 2$ & $\mathrm{H} 3$ & $\mathrm{H} 4$ & $\mathrm{H} 5$ & $\mathrm{H} 6$ & $\mathrm{H} 7$ & $\mathrm{H} 8$ & $\mathrm{H} 9$ & $\mathrm{H} 10$ \\
\hline $\mathrm{H} 1$ & $*$ & & & & & & & & \\
$\mathrm{H} 2$ & 0.00173 & $*$ & & & & & & & \\
$\mathrm{H} 3$ & 0.00173 & 0.00347 & $*$ & & & & & & \\
H4 & 0.00173 & 0.00347 & 0.00347 & $*$ & & & & & \\
H5 & 0.00173 & 0.00347 & 0.00347 & 0.00347 & $*$ & & & & \\
H6 & 0.00347 & 0.00522 & 0.00522 & 0.00522 & 0.00522 & $*$ & & & \\
H7 & 0.01761 & 0.0194 & 0.0194 & 0.0194 & 0.0194 & 0.01404 & $*$ & & \\
H8 & 0.01582 & 0.01761 & 0.01761 & 0.01761 & 0.01761 & 0.01226 & 0.00173 & $*$ & & \\
H9 & 0.01404 & 0.01582 & 0.01582 & 0.01582 & 0.01582 & 0.01049 & 0.00347 & 0.00173 & $*$ \\
H10 & 0.01404 & 0.01582 & 0.01582 & 0.01582 & 0.01582 & 0.01049 & 0.01049 & 0.00873 & 0.00697 & $*$ \\
H11 & 0.01049 & 0.01226 & 0.01226 & 0.01226 & 0.01226 & 0.01049 & 0.01049 & 0.00873 & 0.00697 & 0.01049 \\
\hline
\end{tabular}


Çizelge 4. İvesi haplotipleri arasında Cyt $b$ genine göre genetik uzaklıklar $(K 2 \mathrm{P}+\Gamma)$

\begin{tabular}{|c|c|c|c|c|c|c|c|}
\hline Haplotipler & $\mathrm{HI}$ & $\mathrm{H} 2$ & $\mathrm{H} 3$ & $\mathrm{H} 4$ & $\mathrm{H} 5$ & $\mathrm{H} 6$ & $\mathrm{H} 7$ \\
\hline $\mathrm{HI}$ & ${ }^{*}$ & & & & & & \\
\hline $\mathrm{H} 2$ & 0.00187 & $*$ & & & & & \\
\hline $\mathrm{H} 3$ & 0.00375 & 0.00187 & • & & & & \\
\hline H5 & 0.02100 & 0.01905 & 0.02100 & 0.01518 & $*$ & & \\
\hline H6 & 0.01518 & 0.01326 & 0.01518 & 0.01326 & 0.00564 & * & \\
\hline
\end{tabular}

Akkaraman koyunları, Cyt $b$ genine göre UPGMA genetik ağaçta, H1 (AK05, AK11), H2 (AK16), H3 (AK13), H4 (AK09), H5 (AK08), H6 (AK03, AK07, AK15, AK10, AK14), H7 (AK02), H8 (AK12), H9 (AK01), H10 (AK04) ve H11 (AK06) olmak üzere 11 haplotipe ayrılmıştır (Şekil 5). İvesi koyunları, Cyt $b$ genine göre UPGMA genetik ağaçta, H1 (IV01), H2 (IV07, IV15, IV11, IV05), H3 (IV06), H4 (IV12, IV04, IV09, IV14, IV10, IV02), H5 (IV03) H6 (IV13), H7 (IV16) ve H8 (IV08), olmak üzere 8 haplotipe ayrılmıştır (Şekil 6).

Meadows ve ark. (2007) evcil koyunlarda A, B, C, D, E haplogrupları belirlemişlerdir. Koyun haplogruplarına ait diziler referans alınarak, bu çalışmada belirlenen haplotiplerin (31 haplotip) Cyt $b$ gen dizileri ile birlikte değerlendirilerek, Akkaraman ve İvesi haplotiplerinin haplogruplara veya soylara dağılımını belirlenmiştir. $\mathrm{Bu}$ çalışmadaki haplotiplere ait diziler ile $A, B, C, D$, ve E soylarına ait dizilerle (Meadows ve ark., 2007) birlikte oluşturulan N-J ağacı Şekil 7'de verilmiştir. Şekil 7'deki filogenetik ağaç incelendiğinde, bu çalışmadaki 16 haplotipten, 6'sı B soyunda (IV01, AK13, AK09, IV06, AK16, IV05; \%87 bootstrap değeri), 1'i A soyunda (IV12, \%50 bootstrap değeri), 1'i E soyunda (AK04, \%67 bootstrap değeri) 5'i C soyunda (AK12, AK02, IV16, AK01, IV08, IV03; \%47 bootstrap değeri) yer almış, AK06 ve IV13 farklı kümelenmiştir. Haplotiplerin soylara ayrılmasında bootstrap değerleri A, B ve E soy grubu dışında \%50'nin altında kalmıştır. Meadows ve ark. (2007), koyunları çoğunluk olarak A, B ve C soyuna sahip olduklarını, diğer $D$ ve $E$ soylarının çok nadir ve düşük oranda olduğunu belirtmiştir. Bu çalışmadaki sonuçlar belirtilen görüş ile uyum içerisindedir.
Önceki çalışmalarda, koyunlar Avrupa (A) ve Asya tipler (B) olarak iki büyük gruba ayrılmıştır (Hiendleder ve ark, 1998). Daha sonra, Guo ve ark. (2005), Çin yerli koyun ırklarında, Pedrosa ve ark. (2005) Türkiye yerli koyunlarında (Akkaraman, Karayaka, Hemşin, Morkaraman) üçüncü bir soyun (C) varlığını tespit etmişlerdir. Bununla birlikte Pereira ve ark. (2006), Portekiz yerli koyunlarında düşük frekansta $C$ soyunun bulunduğunu bildirmişlerdir. Daha sonra, Kuzey Kafkasya Karachai koyunlarında (D-loop baz alınarak) daha önce belirtilen üç soydan ayrılan dördüncü bir maternal soyun ( $D$ soyu) varlığı tespit edilmiştir (Tapio ve ark., 2006). Son olarak, Meadows ve ark. (2007), ilk kez beşinci soy olarak E soyunun varlığı'nı Türkiye Tuj ve İvesi koyun ırklarında tespit etmişlerdir. $\mathrm{Bu}$ çalışmada, Cyt $b$ genine göre filogenetik ağaçta AKO1 koyunu AWE ve TJE ile birlikte ayrıldıkları gözlemiştir. Böylece Akkaraman koyunlarında $E$ soyunun varlığı bu çalışmada tespit edilmiştir.

Demirci ve ark. (2013), Türkiye yerli koyunlarında (Morkaraman, İvesi, Akkaraman, Karayaka, Gökçeada, Dağlıç, Kıvırcık, Herik, Karagül, Çine Çaparı, Hemşin, Sakız ve Norduz) mtDNA kontrol bölgesi dizi analizi ile filogenetik ilișkileri araştırmışlardır. Burada HG A=48, HG B = 66, HG $C=43, H G D=2$ ve $H G E=9$ olmak üzere toplam 168 haplotip tespit etmişlerdir. Öner ve ark. (2013), Türkiye yerli koyun ırklarında (Morkaraman, Akkaraman, Karayaka, Kıvırcık, Dağlıç, Hemşin, İvesi, İmroz ve Sakız) yapmış oldukları çalışmada 63 haplotipte, haplotip ve nükleotid farklılığı sırasıyla $0.9496 \pm 0.011$ ve $0.01407 \pm 0.00060$ olarak hesaplamıĢşardır. Filogenetik ağaçta, 63 haplotipinin üç ayrı soya (soy $A, B$ ve $C$ ) ayrıldığını göstermiştir. 


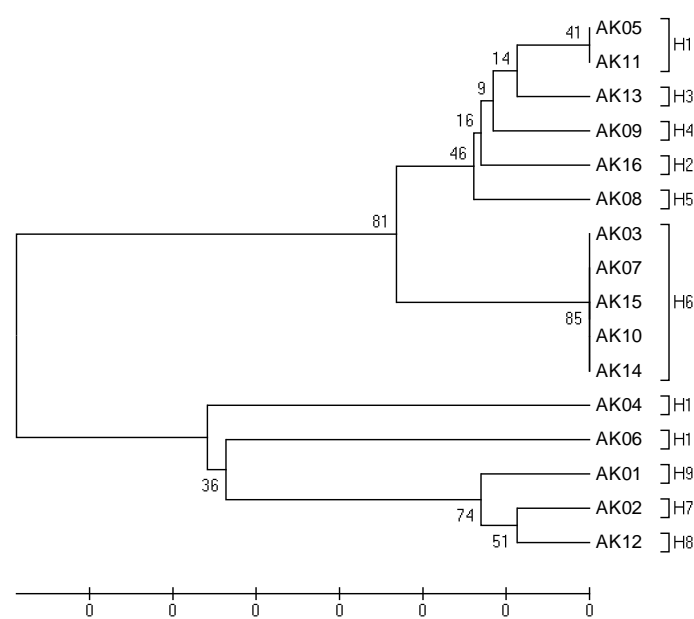

Şekil 5. Akkaraman koyunlarında Cyt $b$ gen bölgesine göre UPGMA ağaç

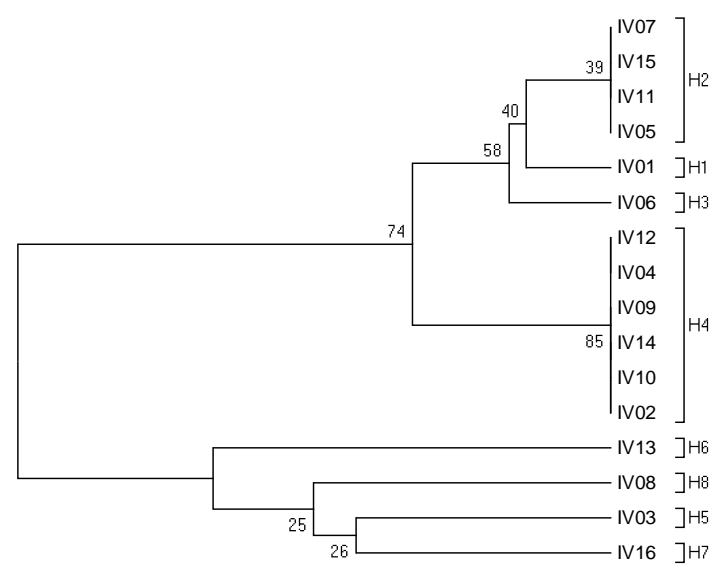

Şekil 6. İvesi koyunlarında $C y t$ ben bölgesine göre UPGMA ağaç

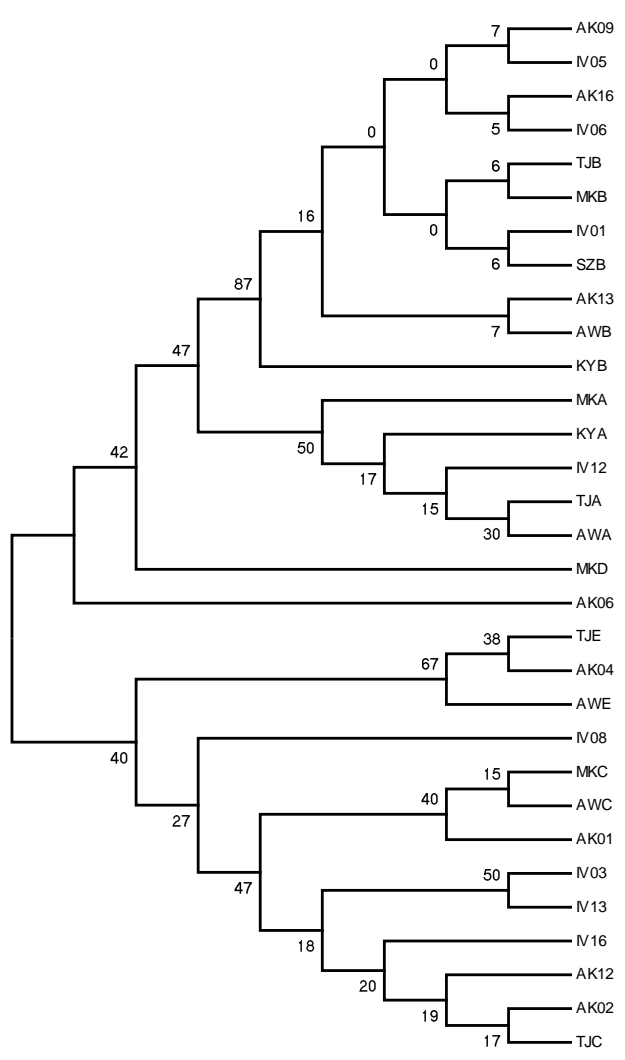

Şekil 7. Cyt b gen dizisine göre Koyun haplogrupları $(\mathrm{K} 2 \mathrm{P}+\Gamma)$

[KR:Karya, NZ:Norduz, TJ:tuj, KK:Karakaş, AW:İvesi CC:Çine çaparı, MK:Morkaraman, KY:Karayaka SZ: Sakız, Meadows ve ark., 2007; AK:Akkaraman, IV:İvesi, Bu çalışma) 


\section{Sonuç ve Öneriler}

Sonuç olarak, Şanlıurfa yöresi Akkaraman ve Ivesi koyunları Cyt $b$ gen dizileri belirlenmiştir. Gen dizi bilgilerine göre Akkaraman ve İvesi koyunları mtDNA polimorfizmi, mtDNA haplotipleri ve haplogrupları (soylarını), haplotipler arasında filogenetik ilişkiler belirlenmiştir. Gen dizi bilgilerinin Gen Bankasında (NCBI) depolanması ile koyunlar üzerinde yapılan filogenetik çalışmalara katkı sağlaması beklenmektedir Ayrıca, çalışma sonuçlarının genetik polimorfizm, biyoçeşitlilik ve hayvan ıslahı çalışmaları ile ulusal gen koruma stratejilerine katkı sağlaması düşünülmektedir..

Teşekkür Bu çalışma, Selahaddin KİRAZ'ın doktora tezinden türetilmiştir. İvesi koyunu kısmı "Phylogenetic Analyse of Awassi sheep in Şanlıurfa Provincebased on Mitochondrial Cytochrome $b$ Gene" başlık ile "2nd International Conference on Agriculture, Forest, Food Sciences and Technologies, İzmir, 2018" kongresinde sözlü bildiri olarak sunulmuştur ve kongre kitabında özet olarak yeralmaktadır. Bu çalışma Harran Üniversitesi Bilimsel Araştırma Projeleri Koordinatörlüğü tarafından desteklenmiştir.

Çıkar Çatışması Beyanı: Makale yazarları aralarında herhangi bir çıkar çatışması olmadığını beyan ederler.

Araştırmacıların Katkı Oranı Beyan Özeti: Yazarlar makaleye eşit oranda katkı sağlamış olduklarını beyan ederler.

\section{Kaynaklar}

Bradley, D.G., Machugh, D.E., Cunningham. P., Loftus, R.T. 1996. Mitochondrial diversity and the origins of african and european cattle. Proceedings of the National Academy of Sciences of the United States of America, 93 (10): 5131-5135.

Guo, J., Du, L.X., Ma, Y.H., Guan, W.J., Li, H.B., Zhao, Q.J., Li, X., Rao, S.Q. 2005. A novel maternal lineage revealed in sheep (Ovis aries). Animal Genetics, 36 (4): 331-336.

Demirci, S., Koban Baştanlar, E., Dağtaş, N. D., Pişkin, E., Engin, A., Ozer, F., Yüncü, E., Doğan, S. A., Togan, I. 2013. Mitochondrial DNA diversity of modern, ancient and wild sheep (Ovis gmelinii anatolica) from Turkey: new insights on the evolutionary history of sheep. PLoS One, 11: 8(12): e81952.

Hiendleder, S., Lewalski, H., Wassmuth, R., Ke, A. 1998a. The complete mitochondrial DNA sequence of the domestic sheep (Ovis aries) and comparison with the other major ovine haplotype. Journal of Molecular Evolution, 47 (4): 441-448.

Hiendleder, S., Mainz, K., Plante, Y., Lewalski, H. 1998b. Analysis of mitochondrial dna indicates that domestic sheep are derived from two different ancestral maternal sources: no evidence for contributions from Urial and Argali sheep. Journal of Heredety, 89 (2): 113-120.

Hiendleder, S., Phua, Sh., Hecht, W. 1999. A diagnostic assay discriminating between two major Ovis aries mitochondrial DNA haplogroups. Animal Genetics, 30 (3): 211213.

Hiendleder, S., Kaupe, B., Wassmut, R., and Janke, A. 2002. Molecular analysis of wild and domestic sheep qestions current nomenclature and provides evidence for domestication from two different subspecies. Proceedings of The Royal Society of London, 269: 893-904.

Joshi, M.B., Rout, P.K., Mandal, A.K., Tyler-Smith, C., Singh, L., Thangaraj, K. 2004. Phylogeography and origin of Indian domestic goats. Molecular Biology Evolution, 21 (3): 454-462.

Kımura, M. 1980. A simple method for estimating evolutionary rate of base substitutions through comparative studies of nucleotide sequences. Journal of Molecular Evolution, 16: 111-120.

Librado, P., Rozas, J. 2009. DnaSP v5: A software for comprehensive analysis of DNA polymorphism data. Bioinformatics, 25: 1451-1452.

Loftus, R. T., Machugh, D. E., Bradley, D. G., Sharp, P. M., Cunningham, P. 1994. Evidence for two independent domestications of cattle. Proceedings of the National Academy of Sciences of the United States of America, 91: 2757-2761.

Luikart, G., Gielly, L., Excoffier, L., Vigne, Jd., Bouvet, J., Taberlet, P. 2001. Multiple maternal origins and weak phylogeographic structure in domestic goats. Proceedings of the National Academy of Sciences of the United States of America, 98 (10): 59275932.

Machugh, D.E., Bradley, D.G. 2001. Livestock genetic origins: goats buck the trend. Proceedings of the National Academy of Sciences of the United States of America, 98 (10): 5382-5384.

Mannen, H., Nagata, Y., Tsujı, S. 2001. Mitochondrial DNA reveal that domestic goat (Capra hircus) are genetically affected by two subspecies of benzoar (Capra 
aegagurus). Biochemical Genetics, 39 (5-6): 145-54.

Meadows, J.R., Cemal, I., Karaca, O., Gootwine, E., Kijas, J.W. 2007. Five ovine mitochondrial lineages identified from sheep breeds of the near East. Genetics, 175 (3): 1371-1379.

Nei, M., Kumar, S. 2000. Molecular evolution and phylogenetics, Oxford University Press, Oxford.

Öner, Y., Calvo, J. H., Elmacl, C. 2013. Investigation of the genetics diversty among native Turkish sheep breeds using mtDNA polymorphism. Tropical Animal Health and Production, 45: 947-951.

Pardeshi, V.C., Kadoo, N.Y., Sainani M.N., Meadows, J.R., Kijas, J.W., Gupta, V.S. 2007. Mitochondrial haplotypes reveal a strong genetic structure for three Indian sheep breeds. Animal Genetics, 38 (5): 460-466.

Pedrosa, S., Uzun, M., Arranz, Jj., Gutierrez-Gil, B., San, Primitivo, F., Bayon, Y. 2005. Evidence of three maternal lineages in near eastern sheep supporting multiple domestication events. Proceedings of The Royal Society $B$, 272 (1577): 2211-2217

Pedrosa, S., Arranz, J.J., Brito, N., Molia, A., San Primitivo, F., Bayón, Y. 2007. Mitochondrial diversity and the origin of Iberian sheep. Genetics Selection Evolution, 39 (1): 91-103.

Pereira, F., Davis, S.J., Pereira, L., Mcevoy, B., Bradley, D.G., Amorim, A. 2006. Genetic signatures of a Mediterranean influence in Iberian Peninsula sheep husbandry. Molecular Biology and Evolution, 23 (7): 1420-1426.

Ryder, M.L. 1984. Sheep. In: Evolution of domesticated animals, Longman, London, 63-85.

Saitou, N., Nei, M. 1987. The neighbor-joining method: a new method for reconstruction phylogenetic trees. Molecular Biology and Evolution, 4: 406-425.

Sambrook, J., Fritsch, E. F., Maniatis, T. 1989. Molecular cloning:A laboratory manual (2nd ed.), 3 vol., Cold-Spring Harbor, New York.

Sultana, S., Mannen, H., Tsuji, S. 2003. Mitochondrial DNA diversity of Pakistani goats. Animal Genetics, 34 (6): 417-421.

Tamura, K., Dudley, J., Nei, M., Kumar, S. 2007. MEGA4: Molecular evolutionary genetics analysis (MEGA) software version 4.0. Molecular Biology and Evolution, 24:15961599.

Tapio, M., Marzanov, N., Ozerov, M.., Cinkulov, M., Gonzarenko, G., Kiselyova, T., Murawskıi M., Vinalass, H., Kantanen , J. 2006. Sheep mitochondrial DNA variation in European, Caucasian, and Central Asian areas. Molecular Biology and Evolution, 23 (9): 1776-1783.

Thompson, J.D., Higgins, D.G., Gibson, T.J., 1994. CLUSTAL W: improving the sensitivity of progressive multiple sequence alignment through sequence weighting, positionsspecific gap penalties and weight matrix choice. Nucleic Acids Research, 22: 46734680.

Troy, C.S., Machugh, D.E., Bailey, J.F., Magee, D.A., Loftus, R.T., Cunningham, P., Chamberlain, A.T., Sykes, B.C., Bradley, D.G. 2001. Genetic evidence for Near-Eastern origins of European cattle. Nature, 410: 1088-1091.

Zeder, Ma., Hesse, B. 2000 . The initial domestication of goats (Capra Hircus) in the Zagros mountains 10.000 years ago. Science, 287 (5461): 2254-2257.

Zeuner, F.E. 1963. A history of domesticated animals. Harper \& Row: New York. 